\title{
Whether Gastrorenal Shunt Embolization Would Benefit the Outcomes of Post Transjugular Intrahepatic Portosystemic Shunt
}

\section{Dongmei Zhao}

First Affiliated Hospital of Anhui Medical University

\section{Mingquan Wang}

First Affiliated Hospital of Anhui Medical University

\section{Guosheng Chen}

First Affiliated Hospital of Anhui Medical University

\section{Guobing Zhang}

First Affiliated Hospital of Anhui Medical University

\section{Chaoxue Zhang}

First Affiliated Hospital of Anhui Medical University

Jiabin Li ( $\sim$ lijiabin@ahmu.edu.cn )

First Affiliated Hospital of Anhui Medical University https://orcid.org/0000-0003-3238-569X

\section{Research Article}

Keywords: Gastrorenal shunts, hepatic encephalopathy, clinical outcome, embolization, transjugular intrahepatic, portal hypertension, rebleeding, ascites, shunt dysfunction, mortality portosystemic shunt

Posted Date: December 13th, 2021

DOI: https://doi.org/10.21203/rs.3.rs-1121231/v1

License: (c) (i) This work is licensed under a Creative Commons Attribution 4.0 International License. Read Full License 


\section{Abstract}

Background \& Aim: Whether the spontaneous portosystemic shunts in cirrhosis who require embolization during transjugular intrahepatic portosystemic shunt (TIPS) remains a therapeutic controversial. This study was retrospectively conducted to evaluate the effectiveness of the gastrorenal shunts (GRS) embolization in cirrhosis post-TIPS

Methods: 70 cirrhotic patients who underwent TIPS in a tertiary-care center were included, of which 43 patients had no GRS and 27 had GRS with embolization during TIPS placement. Then, to assess the outcomes of embolization of GRS on post-TIPS hepatic encephalopathy (HE), clinical relapse, mortality and shunt dysfunction.

Results: During a median follow-up period of 497.01 days, 25 patients (35.7\%) experienced HE, of 14 patients in GRS group and 11 in another $(p=0.026)$. Within 50 days after TIPS, 12 patients performed initial HE in GRS group while 6 in the reference group $(p<0.001)$. After TIPS of $150^{\text {th }}$ to $200^{\text {th }}$, one in the former group and five in another experienced HE $(p<0.001)$. However, there was no significant difference in the 1-year cumulative risk of $\mathrm{HE}(p=0.287)$. Meanwhile, during the 2-year follow-up, the patients performed lower incidence of ascites after GRS embolization with TIPS $(p<0.002)$. And there was no difference in rebleeding, mortality and shunt dysfunction.

Conclusions: TIPS with GRS embolization appeared to be a safe and efficacious procedure in the treatment of portal hypertension with concomitant GRS. Furthermore, the procedure seemed to reduce the recurrences of ascites for a long term observation.

\section{Introduction}

Portal hypertension $(\mathrm{PH})$ is the result of increased resistance to portal blood flow in cirrhosis, accordingly lead to a series of complications such as ascites and variceal rebleeding ${ }^{[1,2]}$, and also should contribute to develop portosystemic vascular connections for the emergence of spontaneous portosystemic shunts (SPSS) ${ }^{[1]}$. SPSS was considered as an advantage compensation of $\mathrm{PH}$ for acting as an actual surgical shunt for 30 years ago ${ }^{[3]}$. Nevertheless, it's a double-edged sword. It could decrease portal blood flow and increase collateral flow, which result in the high incidence of hepatic encephalopathy (HE) and mortality $[4-6]$.

Transjugular intrahepatic portosystemic shunt (TIPS) have been widely regarded as an effective treatment for the complications of $\mathrm{PH}$ in cirrhosis ${ }^{[7,8]}$. Previous studies ${ }^{[9,10]}$ identified that the presence of co-existing SPSS in cirrhosis influence the outcomes such as deterioration of liver function and recurrent HE after TIPS placement. Thereupon, the opinion of the current study ${ }^{[10]}$ showed that by placing a TIPS along with large SPSS embolization, the risk of HE episodes could be decreased and without increasing other complications. However, this standpoint has not been yet fully demonstrated. Moreover, information regarding the long-term effect of the presence of SPSS embolization in TIPS placement is 
lacking, particularly, judging for one specific type of SPSS such as the gastrorenal shunts (GRS) that connect the gastric veins and the left renal vein. GRS is a common collateral vein of SPSS ${ }^{[6]}$, which account for $20.4 \%$ in cirrhotic patients with $\mathrm{PH}^{[11]}$.

Accordingly, this study was undertaken to observe and analysis the outcome of GRS embolization in TIPS placement during the long-term follow-up, then to evaluate the efficacy and safety of the procedure in $\mathrm{PH}$ with concomitant GRS.

\section{Materials And Methods \\ Study design}

We conducted a retrospective review of all patients admitted for the complications of $\mathrm{PH}$ in cirrhotic patients treated with TIPS, from January 2014 to February 2016. Ethic approval for this study was granted by the Ethics Commitment of First affiliated hospital of Anhui Medical University.

In order to be included, patients had to fulfill the following criteria: Inclusion criteria included the following: age > 18 years, known liver cirrhosis based on findings of histological or typical cross-sectional imaging (including ultrasound, computed tomography angiography or magnetic resonance imaging), first treatment for TIPS because of complication of PH. Exclusion criteria were as follows: Child-Pugh scores $>13$, a creatinine level greater than 158 moll per liter, total bilirubin levels three times higher than normal, pregnancy, liver cancer or other cancers, total portal-vein thrombosis, heart failure and those in whom the outcomes could not be followed.

GRS definition. Abdominal CT or MRI was applied for the presence of GRS by a radiologist with expertise in hepatic disease. GRS is characterized as a complete neurovascular pedicle traversing the gastrophrenic ligament, which connects the gastric collateral vein to the left renal vein via the inferior vein of the left curs of the diaphragm and the middle capsular vein, which can provide entrance into the systemic venous system [12]. The presence of GRS as one type of the non-variceal SPSS was considered when the contrast drained along the shunting channel, clearly portraying the inferior vena cava on the angiography of the TIPS procedure.

Accordingly, the entire cohort was categorized into two groups: no GRS group and the presence of GRS group, the former was treated just with TIPS procedure and the latter experienced the presence of GRS embolization during TIPS placement. Then, GRS group and no GRS group tread different paths that lead to the same destination. In this study, the group of no GRS with TIPS is not so much a control group as the standard reference.

\section{TIPS procedure and GRS improvisation}

The TIPS procedure was performed with a standard technique by the same team as previously described $[13,14]$. Briefly, covered or uncovered stents were used, mostly depending on what time the procedure was 
performed. For patients undergoing GRS closure, the spontaneous shunt was plug using coils or tissue glue after successfully puncturing the portal vein via a transjugular approach. During the TIPS procedure, the portosystemic pressure gradient was measured and intravenous heparin was given after the placement.

\section{Follow-up}

After TIPS procedures, patients underwent inpatient monitoring for at least 24 hours, and were followed in the outpatient clinic after hospital discharge at 1-month, 3-month, and subsequent 6-month intervals post procedure. At the time of outpatient evaluation, patients were monitored for assessment of HE, recurrent rebleeding, ascites and corresponding medications. Meanwhile, the level of blood ammonia, liver-renal function tests and the coagulation profile were assessed. As well, all patients with TIPS underwent Doppler ultrasound surveillance of shunt patency.

The end points of follow-up were liver transplantation, mortality or loss to follow up. Then, the development of complications after TIPS placement was recorded until the end study (February 2016). However, it was highlighted that it should be recorded in detail when the patients initially performed HE.

\section{Statistical Analysis}

Calculations were performed with SPSS version 21.0 software. Quantitative variables were performed with Student's $t$ tests, and qualitative variables were compared using either the chi-squared test or Fisher's exact test wherever appropriate. The first time to diagnose HE was described with the cumulative incidence function as competing risks. Kaplan-Meier analysis provides more accurate estimations of the cumulative risk of HE between the two groups. $P$ values less than 0.05 were considered to be significant.

\section{Results}

\section{Patient characteristics}

A total of 97 cirrhotic patients with complications of $\mathrm{PH}$ were admitted to the first affiliated hospital of Anhui Medical University, of which 25 had exclusion criteria for the study and 2 patients lost to follow-up. The remaining 70 patients received TIPS with embolization or not, of which 20 with Child-Pugh class A chose the above therapeutic regimen, for refusing performing endoscopic treatment or other treatments. Thus, the no GRS group and GRS group were comparable in most baseline characteristics (Table 1). Of the 43 patients in no GRS group, and the 27 presence of GRS with TIPS associated embolization. And the two groups have no significant difference in baseline characteristics. In the first year follow-up, there were 70 patients in observation, while 49 patients in the second year follow-up for the deadline or mortality. Only one patient in no GRS group underwent liver transplantation during follow-up in the second year of post-TIPS. 
Table 1

Baseline clinical characteristics of patients.

\begin{tabular}{|c|c|c|c|}
\hline \multirow[t]{2}{*}{ Variable } & \multicolumn{2}{|c|}{ Gastrorenal shunt } & \multirow[t]{2}{*}{$p$ value } \\
\hline & Yes $(n=27)$ & No $(n=43)$ & \\
\hline Age (years) & $50.04 \pm 11.76$ & $50.65 \pm 12.25$ & 0.836 \\
\hline Gender (M) & 21 & 33 & 0.920 \\
\hline Etiology of cirrhosis & & & 0.087 \\
\hline Virus & 17 & 38 & \\
\hline Alcohol & 3 & 2 & \\
\hline Virus+alcohol & 3 & 1 & \\
\hline Others & 4 & 2 & \\
\hline Indication for TIPS & & & 0.942 \\
\hline As cites & 15 & 23 & \\
\hline Avarice bleeding & 9 & 14 & \\
\hline As cites + avarice bleeding & 3 & 6 & \\
\hline Serum total bilirubin (moll/L) & $24.13 \pm 12.30$ & $22.43 \pm 13.92$ & 0.605 \\
\hline Serum albumin (g/L) & $32.59 \pm 6.36$ & $32.56 \pm 5.78$ & 0.980 \\
\hline Serum Creation (moll/L) & $68.06 \pm 17.23$ & $70.5 \pm 21.39^{(1)}$ & 0.619 \\
\hline Serum sodium (mole/L) & $139.8 \pm 2.37^{(1)}$ & $138.31 \pm 4.08^{(1)}$ & 0.096 \\
\hline Serum Kali (mole/L) & $3.68 \pm 0.48^{(1)}$ & $3.89 \pm 0.45^{(1)}$ & 0.081 \\
\hline Child-Pugh (A/B/C) & $8 / 14 / 5$ & $12 / 21 / 10$ & 0.895 \\
\hline Previous HE & 3 & 5 & 0.947 \\
\hline Pyle thrombosis & 20 & 31 & 0.856 \\
\hline Endoscopic treatment & 1 & 5 & 0.249 \\
\hline Appendectomy & 1 & 5 & 0.249 \\
\hline Pre-exist PPG (mhm) & $27.42 \pm 5.04^{(1)}$ & $28.19 \pm 4.73^{(2)}$ & 0.535 \\
\hline
\end{tabular}

Note: Results are presented as means \pm SD for quantitative variables. ${ }^{(1) /(2)}$, The number of the data is missing .

Abbreviations: HE, Hepatic encephalopathy; TIPS, Trans jugular antipathetic post-mortem shunt. PPG, Porto systemic gradient. 


\begin{tabular}{|llll|}
\hline Variable & \multicolumn{2}{l|}{ Gastrorenal shunt } & p value \\
\cline { 2 - 3 } & Yes $(\mathbf{n}=\mathbf{2 7})$ & No $(\mathbf{n}=43)$ & \\
\hline Post-TIPS PPG $(\mathrm{mhm})$ & $20.13 \pm 4.55^{(1)}$ & $21.43 \pm 5.29^{(2)}$ & 0.310 \\
\hline Duration of follow-up (days) & $477.93 \pm 148.21$ & $509 \pm 185.27$ & 0.465 \\
\hline
\end{tabular}

Note: Results are presented as means \pm SD for quantitative variables. ${ }^{(1) /(2)}$, The number of the data is missing .

Abbreviations: HE, Hepatic encephalopathy; TIPS, Trans jugular antipathetic post-mortem shunt. PPG, Porto systemic gradient.

\section{Hepatic encephalopathy}

The median long-term follow-up period was 497.01 (IQR, 330.25-654) days for the entire cohort. During the first year of follow-up, the period of observing HE was 352.41 (IQR, 353-365) days in GRS group and 339.02 (IQR, 315-365) days in no GRS group $(p=0.106)$. And 25 patients $(35.7 \%)$ experienced at least one episode of HE, of 14 patients in GRS group and 11 in another $(p=0.026)$. Of course, the specific episodes of HE were recorded, nine patients in GRS group and 8 in no GRS group developed stage冈-QHE, then were performed $₫ \mathrm{HE}$ in 5 patients and 3 patients, respectively. The distribution of initially performed HE could be seen in the Figure 1. Within 50 days after TIPS, 12 patients performed initial HE in GRS group while 6 in the reference group ( $p<0.001)$. After TIPS of 150th to 200th, one in the former group and five in another $(p<0.001)$. Only one patient performed HE in the 250th day. However, there was no significant difference in the 1-year cumulative risk of HE between the two the groups ( $p=0.287$, Figure 2$)$. In the second year, there was only one patient but not newer performed HE in no GRS group for senile constipation. Fortunately, the incidence of HE was no longer increasing after the 250th post-TIPS, and all the cases of performing HE can be controlled medically with cellulose, protein-restricted diet or branchedchain amino acids (Table 2). 
Table 2

Summary of outcomes categorized according to the presence of gastronome shunts in the first and second year follow-up.

\section{Gastronome Shunt}

\begin{tabular}{|c|c|c|c|c|c|c|c|}
\hline \multirow[t]{2}{*}{ Outcome } & \multirow[t]{2}{*}{ Overall } & \multicolumn{3}{|c|}{ The 1ST year $(n=70)$} & \multicolumn{2}{|c|}{ The $2 n d$ year $(n=49)$} & \multirow{2}{*}{$\begin{array}{l}p^{\#} \\
\text { value }\end{array}$} \\
\hline & & $\begin{array}{l}\text { GRS } \\
(n=27)\end{array}$ & $\begin{array}{l}\text { no GRS } \\
(\mathrm{n}=43)\end{array}$ & $\begin{array}{l}p^{\rrbracket} \\
\text { value }\end{array}$ & $\begin{array}{l}\text { GRS } \\
(n=19)\end{array}$ & $\begin{array}{l}\text { no GRS } \\
(\mathrm{n}=30)\end{array}$ & \\
\hline $\begin{array}{l}\text { Median follow-up } \\
\text { period, days (IQR) }\end{array}$ & $\begin{array}{l}497.01 \\
(330.25- \\
654)\end{array}$ & $\begin{array}{l}352.41 \\
(353- \\
365)\end{array}$ & $\begin{array}{l}339.02 \\
(315- \\
365)\end{array}$ & 0.106 & $\begin{array}{l}543.37 \\
(433- \\
663)\end{array}$ & $\begin{array}{l}608.63 \\
(504.25- \\
739.25)\end{array}$ & 0.465 \\
\hline
\end{tabular}

HE

\begin{tabular}{|c|c|c|c|c|c|c|c|}
\hline Patients, n (\%) & $\begin{array}{l}25 \\
(35.71) a\end{array}$ & $14(56)$ & $11(44)$ & 0.026 & & & \\
\hline $\begin{array}{l}\text { The time of being } \\
\text { HE (IQR) }\end{array}$ & $\begin{array}{l}63.56(8- \\
166.5)\end{array}$ & $\begin{array}{l}42(5.5- \\
28.25)\end{array}$ & $\begin{array}{l}91(11- \\
190)\end{array}$ & 0.149 & & & \\
\hline Child-Hugh (A/B/C) & $6 / 14 / 5$ & $3 / 8 / 3$ & $3 / 6 / 2$ & 0.938 & & & \\
\hline 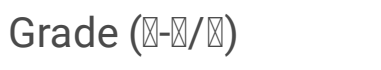 & $17 / 8$ & $9 / 5$ & $8 / 3$ & 1 & & & \\
\hline Bleeding & & & & 1 & & & 0.819 \\
\hline Patients, n (\%) & $\begin{array}{l}12 \\
(17.14) a\end{array}$ & $\begin{array}{l}5 \\
(41.67)\end{array}$ & $\begin{array}{l}5 \\
(41.67)\end{array}$ & & 0 & $2(16.67)$ & \\
\hline $\begin{array}{l}\text { Avarice bleeding, } \mathrm{n} \\
(\%)\end{array}$ & $\begin{array}{l}2 \\
(16.67) b\end{array}$ & 0 & 0 & & 0 & $2(100)$ & \\
\hline $\begin{array}{l}\text { Avarice bleeding, } n \\
(\%)\end{array}$ & $3(25) b$ & $\begin{array}{l}2 \\
(66.67)\end{array}$ & $\begin{array}{l}1 \\
(33.33)\end{array}$ & & & & \\
\hline $\begin{array}{l}\text { Esophageal/gastric } \\
\text { ulcer, } n(\%)\end{array}$ & $\begin{array}{l}7 \\
(58.33) \mathrm{b}\end{array}$ & $\begin{array}{l}3 \\
(42.86)\end{array}$ & $\begin{array}{l}4 \\
(57.14)\end{array}$ & & & & \\
\hline Ascites, n (\%) & $\begin{array}{l}29 \\
(41.43) a\end{array}$ & $\begin{array}{l}5 \\
(17.24)\end{array}$ & $\begin{array}{l}1 \\
4(48.28)\end{array}$ & 0.199 & $2(6.9)$ & $8(27.59)$ & 0.002 \\
\hline
\end{tabular}

Note: HE, Hepatic encephalopathy; GRS, Gastronome Shunts; IQR, inter quartile range.

a Percentages referred to the total number of patients $(n=70)$.

${ }^{b}$ Percentages referred to the total number of patients with bleeding $(n=12)$.

$p^{\llbracket}$ Between GRS group and no GRS group in the first year.

$\mathrm{p}^{\#}$ Between the two groups in 2 years follow-up. 


\section{Gastronome Shunt}

\begin{tabular}{|llllllll|}
$\begin{array}{l}\text { Liver } \\
\text { transplantation, } \mathrm{n} \\
(\%)\end{array}$ & $1(1.43) \mathrm{a}$ & 0 & 0 & & 0 & $1(100)$ & 1 \\
\hline Mortality, n (\%) & $5(7.14) \mathrm{a}$ & $1(20)$ & $4(80)$ & 0.642 & 0 & 0 & \\
\hline $\begin{array}{l}\text { Shunt dysfunction, } \\
\mathrm{n}(\%)\end{array}$ & $\begin{array}{l}8 \\
(11.43) \mathrm{a}\end{array}$ & $1(12.5)$ & $2(25)$ & 1 & $2(25)$ & $3(37.5)$ & 1 \\
\hline
\end{tabular}

Note: HE, Hepatic encephalopathy; GRS, Gastronome Shunts; IQR, inter quartile range.

a Percentages referred to the total number of patients $(n=70)$.

${ }^{b}$ Percentages referred to the total number of patients with bleeding $(n=12)$.

$p^{\square}$ Between GRS group and no GRS group in the first year.

$p^{\#}$ Between the two groups in 2 years follow-up.

\section{Other outcomes}

During follow-up, there were no significant differences in the 1-year incidences of clinical relapse between the two groups. And the incident of clinical relapse includes rebleeding (17.14\%) and recurrences of ascites $(41.43 \%)$. A total of 10 patients performed rebleeding in the first year, of which 5 patients in GRS group, other 5 in no GRS group. The above patients underwent endoscopy, the results showed that the etiology of rebleeding was diagnosed for variceal rebleeding (3 patients) and esophageal or gastric ulcer (7 patients), while only 2 patients performed variceal rebleeding for the narrow of stent in the second year of follow-up. As the other adverse event of clinical relapse, following the groups between GRS and the reference, activities presented in 19 patients ( 5 versus 14 ) in the first year of follow-up ( $p=0.199$ ), and 10 (2 versus 8 ) occurred in the second year of follow-up. Meanwhile, during the 2 years follow-up, the patients performed lower incidence of ascites after GRS embolization with TIPS $(p<0.002)$ (Table 2$)$.

There were five patients died, of which one in GRS groups and four in no GRS group. As well, no significant differences were observed between the two groups in the 1-year incidences of death $(p=0.642)$ (Table 2). The main etiology of death was liver dysfunction, only one patient died for cerebral vascular accident. And there was no death in the second year.

During follow-up, $11.43 \%$ experienced TIPS stent dysfunction, of which 3 out of 70 patients in the first year, while 5 out of 49 appeared in the second year, and no one experience the second dysfunction of TIPS stent. The incidences of shunt dysfunction in the first year of follow-up were $12.5 \%$ in the GRS group and $25 \%$ in the no GRS group, and turned to $25 \%$ and $37.5 \%$ respectively in the second year, showing nonsignificant difference $(p=1.0)$ (Table 2).

\section{Discussion}


The results from the present study showed that GRS embolization in addition to TIPS was associated with the higher 1-year incidences of HE but had no difference in clinical relapse, mortality or shunt dysfunction. Furthermore, the distribution of initially performed HE was characterized by obvious stages, which performed significant difference between the two groups $(p<0.001)$. However, there was no significant difference in the 1-year cumulative risk of HE $(p=0.287)$. In addition, during up to two years follow-up, there was no longer increased incidence of HE after the 250th post-TIPS, and all the cases of performing HE can be controlled medically with cellulose, protein-restricted diet or branched-chain amino acids. And during the whole 2 years follow-up, the GRS group performed lower incidence of ascites after GRS embolization with TIPS $(p<0.002)$. An important showing of a relatively precise presence of HE after TIPS was recorded through the long-term follow-up. The precious article showed the incidence of new onset or worsening HE was up to be $50 \%[15,16]$. In our study, the overall post-procedural HE rate is $35.7 \%(25 / 70)$, but the HE rate in patients with GRS is $56 \%$, compared to $44 \%$ in patients without a shunt. The results of this study clearly showed that the patients with GRS undergoing TIPS significantly perform the higher incidence of HE in the statistical. The reasons for the result may be as follows. TIPS with embolotherapy may increase the incidence of shunt dysfunction and liver dysfunction, for a relative growth of portal venous flow in patients with GRS, contrasting with whom has not formed a spontaneous shunt. The extrapolation can be testified by the poor liver function and improved renal function. In addition, the existence of shunts induces excessive portosystemic shunts, thereby increasing the incidence of HE episodes. Moreover, in our study, the distribution of initially performed HE was characterized by obvious stages. Specifically, HE is mostly found within 50 days or as late as the 250th after TIPS, in which only 5 patients over half years, similar to the previous report ${ }^{[17]}$. And also, the stages have significant difference between the two groups $(p<0.001)$. The patients with GRS embolization after TIPS more tend to be HE in the earlier stage, while the patients with no GRS undergoing TIPS also performance HE obviously in the late period. We speculated that the early or the late occurrences of HE may respectively relate to the insufficient liver function and the development of novel or cannibalization of occluded GRS, which was consistent with the previous viewpoint ${ }^{[5]}$. However, there was no significant difference in the 1-year cumulative risk of HE between the two groups $(p=0.287)$. Our finding might be explained by the previous study ${ }^{[10]}$ that a significantly increased risk of HE was only found in patients with a large SPSS. Then, in the later research, we need to pay attention to the diameter of GRS. During the second year of follow-up, 49 followed patients (48/49, 97.96\%) present HE-free. Fortunately, all patients respond well to standard treatment for $\mathrm{HE}$ and no death is associated with $\mathrm{HE}$. Because of the long-term follow-up, we could mainly understand the dynamic change of $\mathrm{HE}$, then draw the conclusion pertinently that GRS embolization during TIPS procedure have no influence on the presence of HE after 1 year of post-TIPS, although the earlier performance of HE was significance.

The rates of rebleeding and ascites recurrence post-TIPS in our study had the similar and difference with those present articles ${ }^{[18,19]}$. Dissegna ${ }^{[18]}$ reported that only $3 \%$ patient experienced two episodes of rebleeding within 1 year, while in our study, the rate of rebleeding was $14.3 \%$ (10/70). However, our results showed that the rates of clinical relapse did not differ significantly between the patents with GRS embolization and without GRS, indicating that the procedure had no deterioration on clinical outcomes. 
Furthermore, GRS embolization with TIPS decreased the recurrences of ascites for the long-term of 2-year follow-up. This finding of our study has not been proposed in other reports ${ }^{[9,20]}$ that may be due to the long-term follow-up. Thus, in evaluating the outcome of GRS embolization with TIPS, the long-term follow-up should be put forward. The study of $\mathrm{He}$ et al. provided the similar results and strongly explained the factor by the shunt patency. As well, no significant differences in mortality were observed, which is consistent with the previous report ${ }^{[10]}$. Overall shunt dysfunction was observed in $11.43 \%$ of our study, which was similar to most other studies on TIPS stent ${ }^{[10,19]}$, and there was no difference in shunt dysfunction between our research groups. And reasonably, the higher incidence of shunt dysfunction was found in the second year than in the first year.

Our report has several uniqueness. Firstly, the long-term follow-up, more convincing to reveal the truth of GRS embolization with TIPS. Secondly, clearly describe the stages of HE performance. Finally, the present study only for GRS, not SPSS that including all kinds, was limitless. However, the inherent limitations of this study included the retrospective analysis, missing data, the diameter of GRS and the inarticulate TIPS stent.

In conclusion, our study showed that GRS embolization in addition to TIPS was more likely to perform HE, which showed difference on the stages but no difference on the cumulative risk. And with the long-term follow-up, GRS embolization with TIPS reduced the recurrences of ascites and had no impact on rebleeding, mortality and shunt dysfunction. Thus, we suggest the profit of GRS embolization during TIPS placement on the cirrhosis with GRS. A lot of large, prospective studies are warranted to confirm our findings.

\section{Declarations}

Concise title: Outcome of GRS embolization with TIPS

Conflicts of Interest:The authors have no conflicts to disclose.

Funding declaration:There was no financial support.

\section{References}

1. Garcia-Tsao G, Abraldes JG, Berzigotti A, Bosch J. Portal hypertensive bleeding in cirrhosis: Risk stratification, diagnosis, and management: 2016 practice guidance by the American Association for the study of liver diseases. Hepatology 2017;65:310-335.

2. de Franchis R, Baveno VI Faculty. Expanding consensus in portal hypertension: Report of the Baveno VI Consensus Workshop: Stratifying risk and individualizing care for portal hypertension. J Hepatol 2015;63:743-752.

3. Ohnishi K, Sato S, Saito M, Nakayama T, Saito M, Chin N, lida S, Nomura F, Okuda K. Clinical and portal hemodynamic features in cirrhotic patients having a large spontaneous splenorenal and/or 
gastrorenal shunt. Am J Gastroenterol 1986;81:450-455.

4. Nardelli S, Riggio O, Gioia S, Puzzono M, Pelle G, Ridola L.Total area of spontaneous portosystemic shunts independently predicts hepatic encephalopathy and mortality in liver cirrhosis. J Hepatol 2020;72(6):1140-1150.

5. Laleman W, Simon-Talero M, Maleux G, Perez M, Ameloot K, Soriano G, Villalba J, Garcia-Pagan JC, Barrufet M, Jalan R, Brookes J, Thalassinos E, Burroughs AK, Cordoba J, Nevens F. Embolization of large spontaneous portosystemic shunts for refractory hepatic encephalopathy: a multicenter survey on safety and efficacy. Hepatology 2013;57:2448-2457.

6. Simón-Talero M, Roccarina D, Martínez J, Lampichler K, Baiges A, Low G, Llop E, Praktiknjo M, Maurer MH, Zipprich A, Triolo1 M, Vangrinsven G, Garcia-Martinez R, Dam A, Majumdar A, Picón C, Toth D, Darnell A, Abraldes JG, Lopez M, Kukuk G, Krag A, Baňares R, Laleman W, Mura VL, Ripoll C, Berzigotti A, Trebicka J, Calleja JL, Tandon P, Hernandez-Gea V, Reiberger T, Albillos A, Tsochatzis EA, Augustin S, Genescà J. Association between portosystemic shunts and increased complications and mortality in patients with cirrhosis. Gastroenterology 2018;154:1694-1705.

7. Vizzutti F, Schepis F, Arena U, Fanelli F, Gitto S, Aspite S, Turco L, Dragoni G, Laffi G, Marra F. Transjugular intrahepatic portosystemic shunt (TIPS): current indications and strategies to improve the outcomes. Intern Emerg Med 2020;15(1):37-48.

8. Bureau C, Thabut D, Oberti F, Dharancy S, Carbonell N, Bouvier A, Mathurin P, Otal P, Cabarrou P, Péron JM, Vinel JP. Transjugular Intrahepatic Portosystemic Shunts With Covered Stents Increase Transplant-Free Survival of Patients With Cirrhosis and Recurrent Ascites. Gastroenterology 2017; 152:157-163.

9. Borentain P, Soussan J, Resseguier N, Botta-Fridlund D, Dufour JC, Gérolami R, Vidal V. The presence of spontaneous portosystemic shunts increases the risk of complications after transjugular intrahepatic portosystemic shunt (TIPS) placement. Diagn Interv Imaging 2016;97:643-650.

10. He C, Lv Y, Wang Z, Guo WG, Tie J, Li K, Niu J, Zuo L, Yu TL, Yuan XL, Chen H, Wang QH, Liu HB, Bai W, Wang EX, Xia DD, Luo BH, Li XM, Yuan J, Han N, Zhu Y, Wang JH, Yin ZX, Fan DM, Han G. Association between non-variceal spontaneous portosystemic shunt and outcomes after TIPS in cirrhosis. Dig Liver Dis 2018; ii: S1590-8658(18)30766-7.

11. Achiwa S, Hirota S, Kako Y, Takaki H, Kobayashi K, Yamakado K. Radiological anatomy of spontaneous splenorenal shunts in patients with chronic liver disease. Jpn J Radiol 2017; 35: 206214.

12. Vidal-González J, Quiroga S, Simón-Talero M, Genescà J. Anatomy of spontaneous splenorenal and gastrorenal venous anastomoses. Review of the literature. Surg Radiol Anat 1998;20(2):129-34.

13. Jiang Q, Wang MQ, Zhang GB, Wu Q, Xu JM, Kong DR. Transjugular intrahepatic portosystemic shunt combined with esophagogastric variceal embolization in the treatment of a large gastrorenal shunt. World J Hepatol 2016;8:850-857.

14. Liu C, Wang HB, Yu YQ, Wang MQ, Zhang GB, Xu LY, Wu JM. Resting-state functional magnetic resonance study of brain function changes after TIPS operation in patients with liver cirrhosis. 
Zhonghua Yi Xue Za Zhi 2016;96:3787-3792.

15. Fonio P, Discalzi A, Calandri M, Doriguzzi Breatta A, Bergamasco L, Martini S, Ottobrelli A, Righi D, Gandini G. Incidence of hepatic encephalopathy after transjugular intrahepatic portosystemic shunt (TIPS) according to its severity and temporal grading classification. Radiol Med (Torino) 2017;122(9):713-21.

16. Riggio O, Nardelli S, Moscucci F, Pasquale C, Ridola L, Merli M. Hepatic encephalopathy after transjugular intrahepatic portosystemic shunt. Clin Liver Dis 2012;16:133-146.

17. Kerlan RK Jr, LaBerge JM, Baker EL, Wack JP, Marx M, Somberg KA, Gordon RL, Ring EJ. Successful reversal of hepatic encephalopathy with intentional occlusion of trans jugular intrahepatic portosystemic shunts. J Vasc Interv Radiol 1995;6:917-921

18. Dissegna D, Sponza M, Falleti E, Fabris C, Vit A, Angeli P, Piano S, Cussigh A, Cmet S, Toniutto P. Morbidity and mortality after transjugular intrahepatic portosystemic shunt placement in patients with cirrhosis. Eur J Gastroenterol Hepatol 2019;31(5):626-632.

19. Y Lv, CY He, ZY Wang, WG Guo, JH Wang, WBai, L Zhang, QH Wang, HB Liu, BH Luo, J Niu, K Li, J Tie, ZX Yin, DM Fan, GH Han. Association of Nonmalignant Portal Vein Thrombosis and Outcomes after Transjugular Intrahepatic Portosystemic Shunt in Patients with Cirrhosis. Radiology 2017;285:9991010.

20. Lynn AM, Singh S, Congly SE, Disha K, David HJ, Russell HW, Patrick SK, James CA, Michael DL. Embolization of portosystemic shunts for treatment of medically refractory hepatic encephalopathy. Liver Transpl 2016;22:723-731.

\section{Figures}




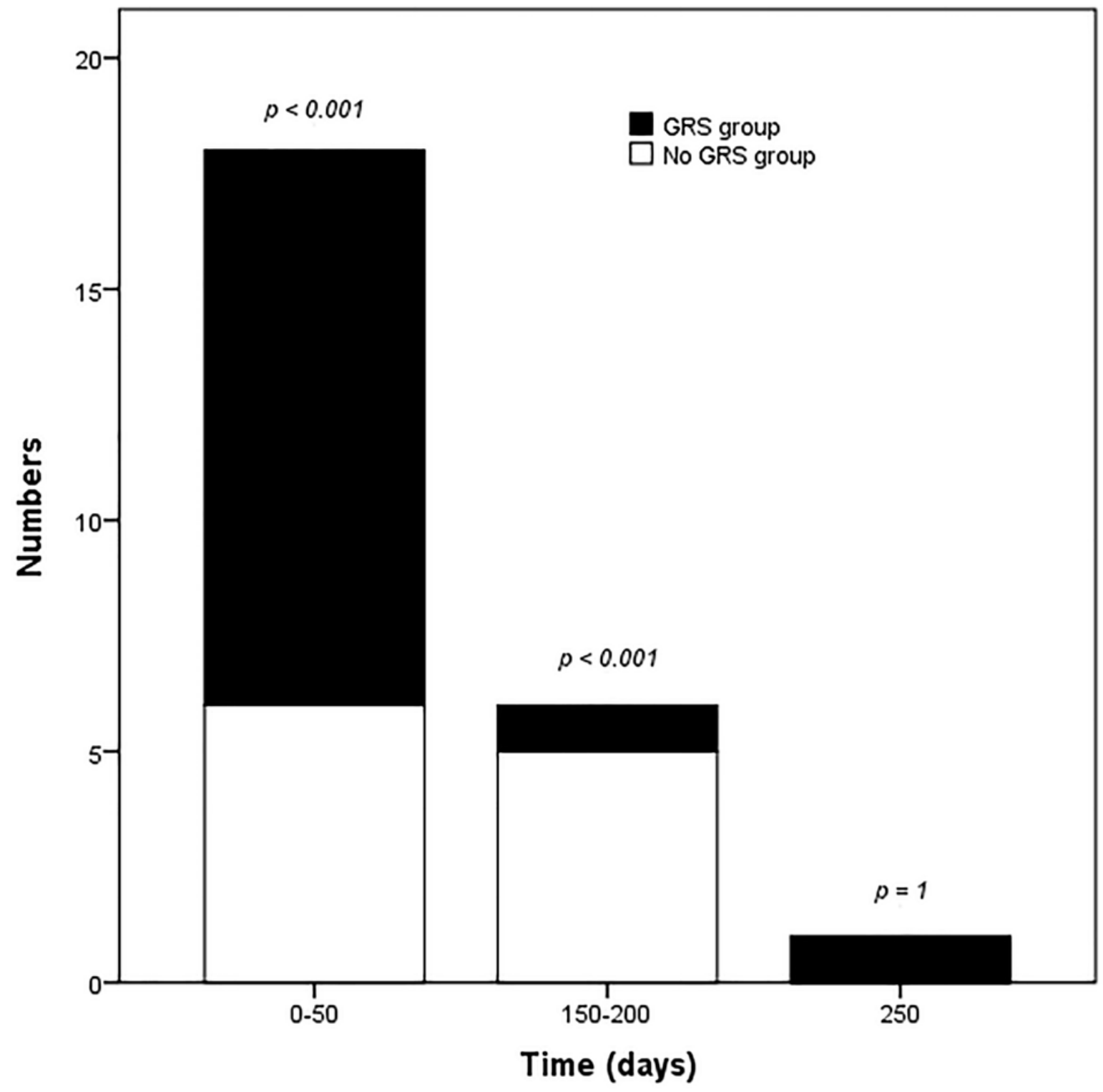

Figure 1

Of course, the specific episodes of HE were recorded, nine patients in GRS group and 8 in no GRS group developed stage $\varangle-\varangle \mathrm{HE}$, then were performed $\otimes \mathrm{HE}$ in 5 patients and 3 patients, respectively. The distribution of initially performed HE could be seen in the Figure 1. 


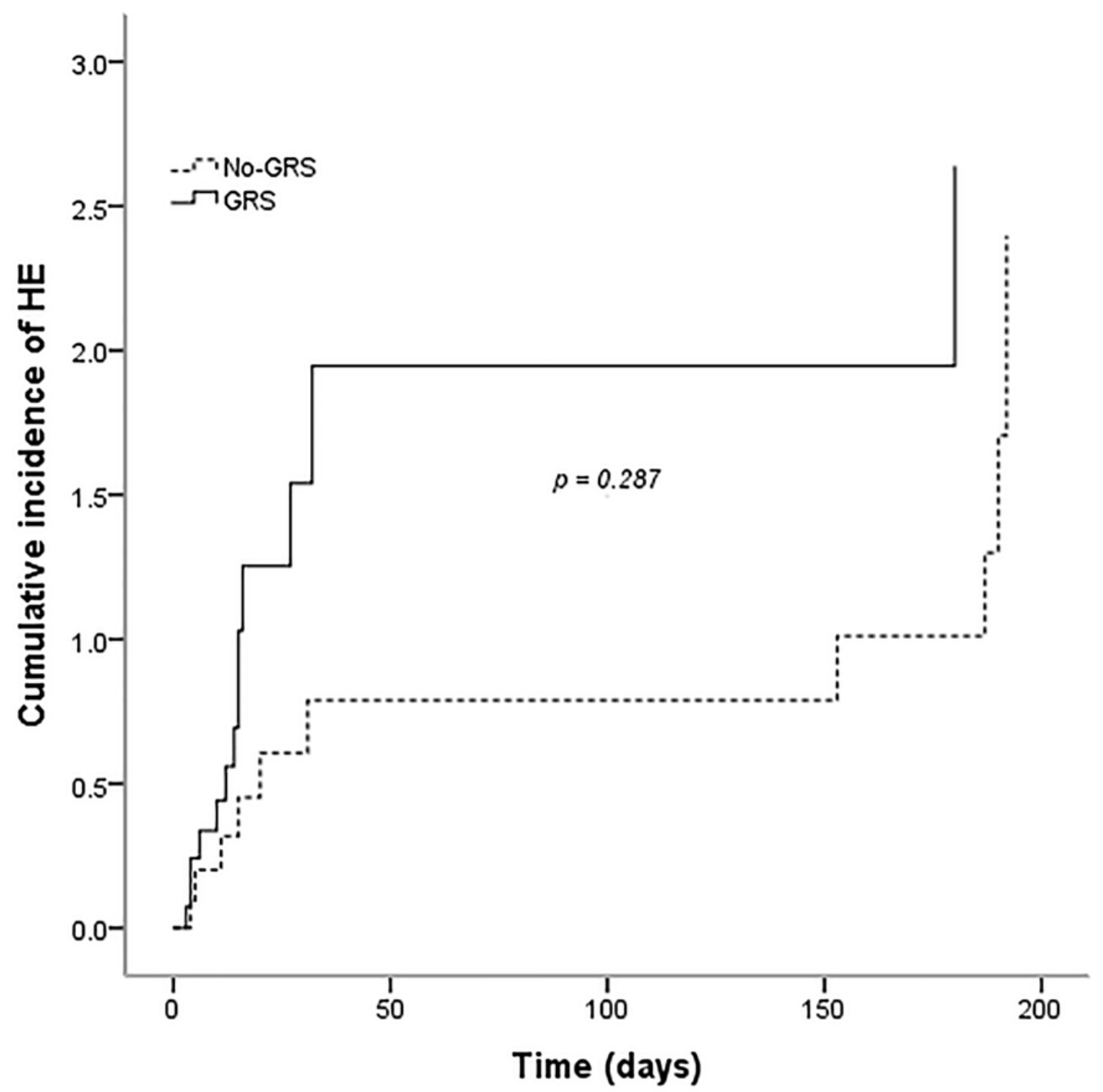

\section{Figure 2}

Within 50 days after TIPS, 12 patients performed initial HE in GRS group while 6 in the reference group ( $p$ $<0.001)$. After TIPS of 150th to 200th, one in the former group and five in another $(p<0.001)$. Only one patient performed $\mathrm{HE}$ in the 250th day. However, there was no significant difference in the 1-year cumulative risk of HE between the two the groups $(p=0.287$, Figure 2$)$. 